\title{
SAXS Study of Influence of Gemini Surfactant, 1,1'-(1,4-butanediyl)bis 3-cyclododecyloxymethylimidazolium di-chloride, on the Fully Hydrated DMPC
}

\author{
Z. Pietralik ${ }^{a}$, M. TAube $^{a}$, A. Skrzypczak ${ }^{b}$ And M. KozAK ${ }^{a, *}$ \\ ${ }^{a}$ Department of Macromolecular Physics, Faculty of Physics, A. Mickiewicz University \\ Umultowska 85, 61-614 Poznań, Poland \\ ${ }^{b}$ Institute of Chemical Technology and Engineering, Poznań University of Technology \\ Marii Skłodowskiej-Curie 2, 61-542 Poznań, Poland
}

\begin{abstract}
The study has been performed on model systems of biological membranes obtained on the basis of 1,2-dimyristoyl-sn-glycero-3-phosphocholine (DMPC) and cationic gemini surfactant - derivative of 1,1'-(1,4-butane)bis 3-alkyloxymethylimidazolium chlorides with cyclic chains. The small angle X-ray scattering SAXS results implied a gradual disappearance (as a function of surfactant concentration) of the lamellar phase typical of DMPC and formation of unilamellar phase — probably a bicellar phase.
\end{abstract}

PACS numbers: 61.05.cf, 87.16.dt, 87.14.Cc, 82.70.Uv

\section{Introduction}

Fully hydrated phospholipids in nature usually form relatively ordered planar bilayer structures or micelles (unilamellar or multilamellar vesicles) [1, 2]. However, in mixtures of long-chain phospholipids with short-chain phsopholipids or surfactants the discoidal (bicellar) phase can be also formed [3, 4]. Such mixed surfactant-lipid systems have been studied by a number of experimental techniques such as: small angle neutron and X-ray scattering $[5,6]$, dynamic light scattering $[7,8]$, nuclear magnetic resonance (NMR) spectroscopy $[9,10]$, electron spin resonance (ESR) [9], dielectric spectroscopy [11], Fourier transform infrared spectroscopy [12,13] or differential scanning calorimetry [14, 15].

Here, we report on the interactions of a gemini surfactant with phospholipid studied using small-angle X-ray scattering (SAXS). We investigated the influence of a gemini surfactant $\left(1,1^{\prime}\right.$-(1,4-butanediyl)bis 3 -cyclododecyloxymethylimidazolium) on the structure and phase behavior of aqueous suspensions of the fully hydrated 1,2-dimyristoyl-sn-glycer0-3-phosphatidylcholine (DMPC). SAXS studies yield information about changes in the bilayer structure and phase behavior of DMPC. Fully hydrated DMPC form a lamellar liquid-crystalline $\left(L_{\alpha}\right)$ phase over $24^{\circ} \mathrm{C}$ and also two lamellar gel phases - planar gel $\left(L_{\beta^{\prime}}\right)$ and rippled gel $\left(P_{\beta^{\prime}}\right)$ phases. The $L_{\beta^{\prime}}$ and $P_{\beta^{\prime}}$ phases are separated by a pretransition at about $15^{\circ} \mathrm{C}[16]$.

* corresponding author; e-mail: mkozak@amu.edu.pl
The gemini surfactant (also known as dimeric surfactants) is made up of two amphiphilic head groups connected at the same level or close to the head group by a spacer group (Fig. 3) [17].

The presence of a spacer chain permits the synthesis of Gemini surfactants with great variety of chemical structures. Gemini surfactants show largely improved properties in comparison to conventional (monomeric) surfactants [17]:

- Dimeric surfactants are characterized by a cmc value (critical micellization concentration) much lower (one or two orders of magnitude) than that of normal (monomeric) surfactants with equivalent hydrophobic chain length.

- Gemini surfactants as surface tension reducers are much more efficient than the corresponding conventional surfactants [17].

These surfactants make a novel group of compounds, which can be used as potential components of delivery agents in gene therapy [18]. The potential nonviral liposomal genetic delivery systems were obtained empirically by modulating phospholipid and surfactant structures (particularly dicationic quaternary ammonium surfactants - gemini surfactants) [19-21].

The low concentration of Gemini surfactants in delivery systems used in gene therapy has also a very positive effect on the cytotoxicity. So far, several studies have demonstrated the efficiency of Gemini surfactant mediated delivery of DNA in vivo [19-21]. 


\section{Materials and methods}

\subsection{Synthesis of the gemini surfactant}

Gemini surfactant - 1,1'-(1,4-butanediyl)bis 3-cyclododecyloxymethylimidazolium di-chloride (Gcyclo) was prepared by the reaction of $1,4-\mathrm{di}(1-$ -imidazolyl)butane and chloromethylcyclododecyl ether in anhydrous benzene according to the procedure described earlier by Urbanik et al. [22]. Chloromethylcyclododecyl ether was prepared by passing HCl-gas through a mixture of formaldehyde and cyclododecanol [23]. The method of synthesis of 1,4-di(1-imidazolyl)butane was also described earlier [24]. Prepared 1,1'-(1,4-butanediyl)bis 3cyclododecyloxymethylimidazolium di-chloride was purified by crystallization process from ethyl acetate/methanol $(1: 1, \mathrm{v} / \mathrm{v})$ solution. The melting point of the colorless plate-like crystals of Gcyclo is $183-185^{\circ} \mathrm{C}$. The chemical structure of $1,1^{\prime}-(1,4$-butanediyl)bis 3-cyclododecyloxymethylimidazolium di-chloride is presented in Fig. 1.

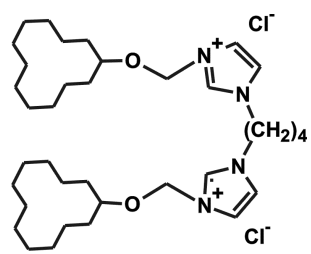

Fig. 1. Chemical structure of the gemini surfactant 1,4-bis[(butane)imidazole-1-yl-3-dodecyloxymethyl di-chloride (Gcyclo).

\subsection{Sample preparation}

The phospholipid DMPC was obtained from Avanti Polar Lipids (USA). The homogeneous $10 \%$ solutions of DMPC (in $50 \mathrm{mM} \mathrm{K}_{2} \mathrm{HPO}_{4} / \mathrm{D}_{2} \mathrm{O} \mathrm{pH} 6.5$ ) and mixtures of DMPC with $0.05,0.1,0.5$ and $1 \%$ Gcyclo surfactant were prepared by the 10 cycles of sonication at $303 \mathrm{~K}$ for 30 min and cooling at $278 \mathrm{~K}$ [25].

\section{3. $S A X S$ studies}

The small angle X-ray scattering measurements were performed on the Beam Line I711 [26, 27] at the MAXII storage ring of the MAX-Lab (Lund, Sweden) using the synchrotron radiation $(\lambda=0.1066 \mathrm{~nm})$ and the MarCCD $165 \mathrm{~mm}$ detector. The phospholipid-surfactant samples $\left(0.1 \mathrm{~cm}^{3}\right)$ were sealed in quartz capillaries $(1 \mathrm{~mm})$ and placed in thermostated capillary holder mounted in an evacuated sample chamber. The measurements were performed at temperatures ranging from 279 to $303 \mathrm{~K}$. The background scattering pattern for the buffer solution was collected before and after data collection for phospholipid samples. The sample-to-detector distance was $1.5 \mathrm{~m}$, which leads to the scattering vector range $0.1<s<3.55 \mathrm{~nm}^{-1}$ (where $s=4 \pi \sin \theta / \lambda, 2 \theta$ is the scattering angle and $\lambda=0.1066 \mathrm{~nm}$ is the $\mathrm{X}$-ray wavelength). The detector momentum transfer axis ( $s$-axis) was calibrated using silver behenate [28].

All data sets were normalized to the incident beam intensity, corrected for detector response and integrated using SAXS data reduction software Bli711 [27].

The scattering of the buffer was subtracted using the program package PRIMUS and the positions of the maxima on the SAXS curves were fitted by the program PEAK [29].

\section{Results and discussion}

The SAXS experiments were performed on pure $10 \%$ 1,2-diheptanoyl-sn-glycero-3-phosphocholine (DMPC) suspension (which was used as the references system) and the DMPC-Gcyclo mixtures as a function of temperature (from $279 \mathrm{~K}$ to $303 \mathrm{~K}$ ).

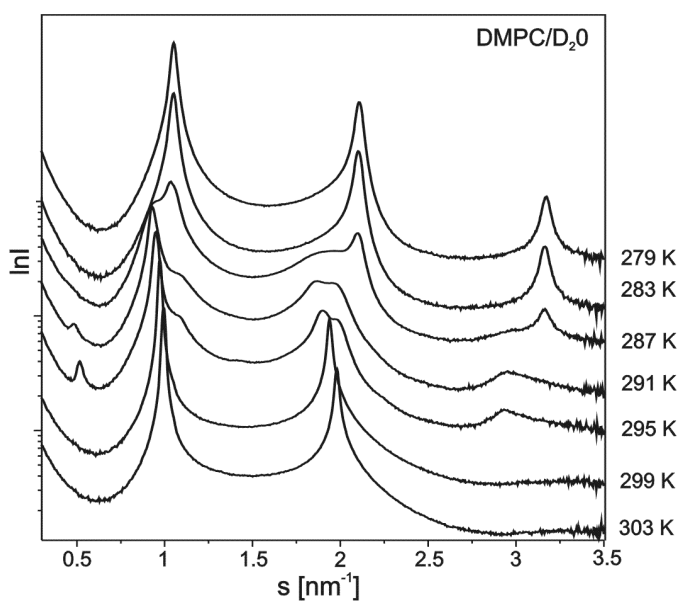

Fig. 2. SAXS results for the references system $\mathrm{DMPC} / \mathrm{D}_{2} \mathrm{O}$. Curves are shown for temperature range 279-303 K.

The scattering data collected for pure DMPC suspension are presented in Figs. 2-6. This system forms in water typical lamellar structures. Below $287 \mathrm{~K}$, the diffraction pattern of DMPC shows three strong peaks characterized by $d_{001}=5.98 \mathrm{~nm}, d_{002}=2.98 \mathrm{~nm}$ and $d_{003}=1.98 \mathrm{~nm}$.

With increasing temperature a pretransition at about $288 \mathrm{~K}$ is observed. After the pretransition the $d$-spacing increased to $6.77 \mathrm{~nm}$ in the ripple gel phase of DMPC.

Above the temperature of $295 \mathrm{~K}$ in the liquid-crystalline phase $L_{\alpha}$ the bilayer thickness decreased. At $303 \mathrm{~K}, L_{\alpha}$ phase is characterized by $d$-spacing 6.3 and $3.17 \mathrm{~nm}$. These values are in good agreement with the results of previous studies $[6,30,31]$. The temperature dependence of the lamellar lattice constant $d$ of fully hydrated DMPC dispersion and the DMPC-Gcyclo mixtures is presented in Fig. 7.

The addition of the gemini surfactant to DMPC system significantly changed the scattering pattern, which 


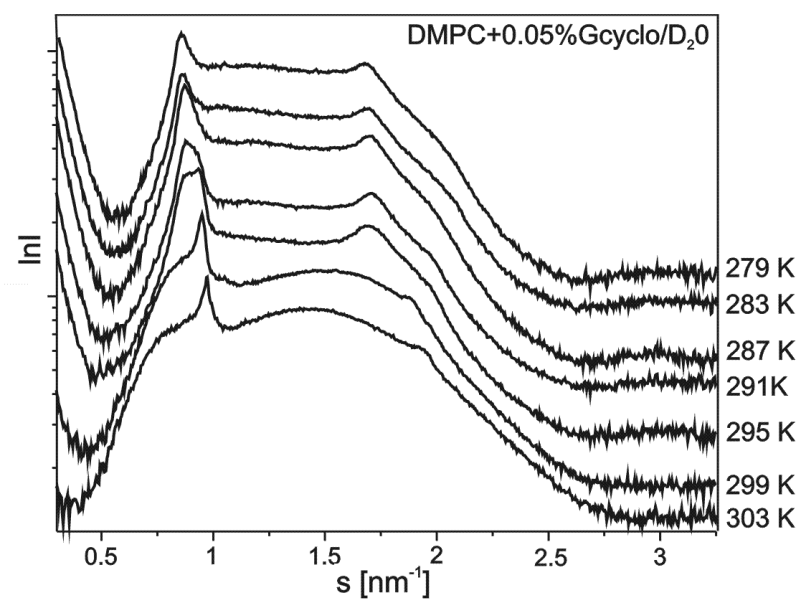

Fig. 3. SAXS data recorded for DMPC/0.05\%Gcyclo/ $\mathrm{D}_{2} \mathrm{O}$. Curves are shown for temperature range 279-303 K.

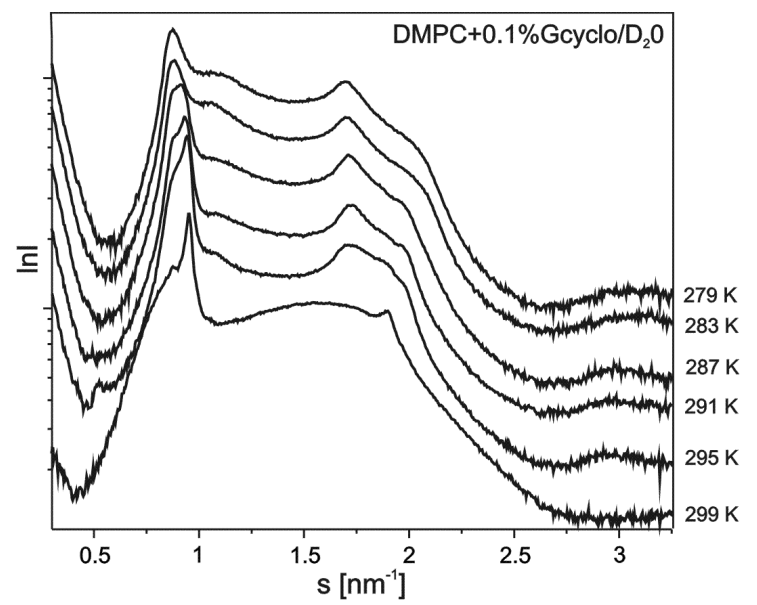

Fig. 4. SAXS data recorded for DMPC/0.1\%Gcyclo/ $\mathrm{D}_{2} \mathrm{O}$. Curves are shown for temperature range 279-303 K.

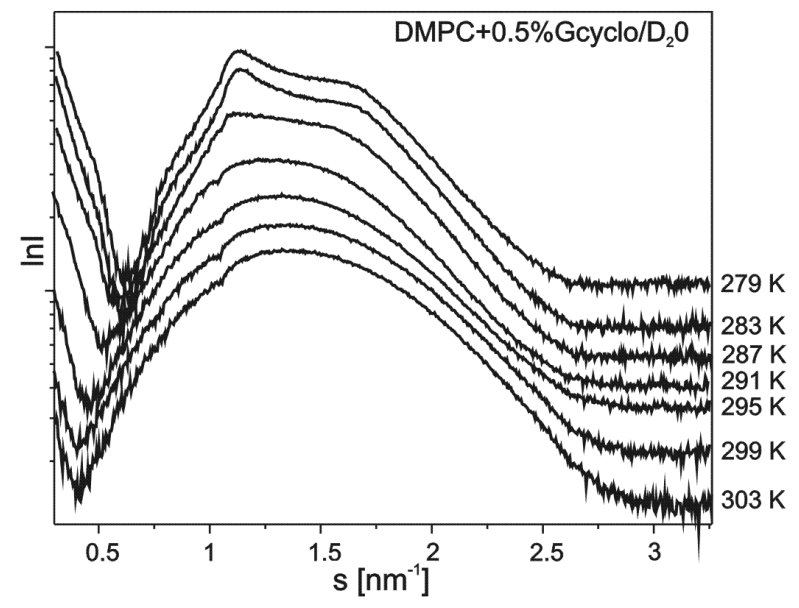

Fig. 5. SAXS data recorded for DMPC/0.5\%Gcyclo/ $\mathrm{D}_{2} \mathrm{O}$. Curves are shown for temperature range 279-303 K.

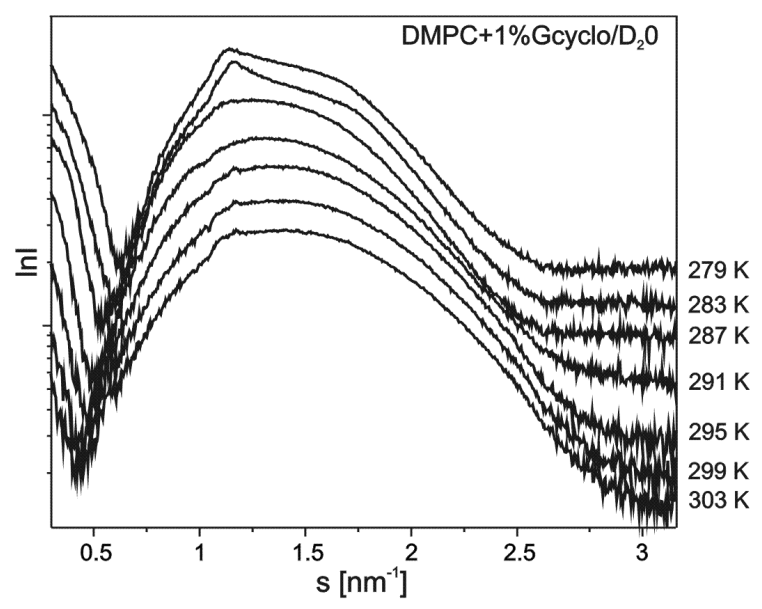

Fig. 6. SAXS data recorded for DMPC/1\%Gcyclo/ $\mathrm{D}_{2} \mathrm{O}$. Curves are shown for 279-303 K.

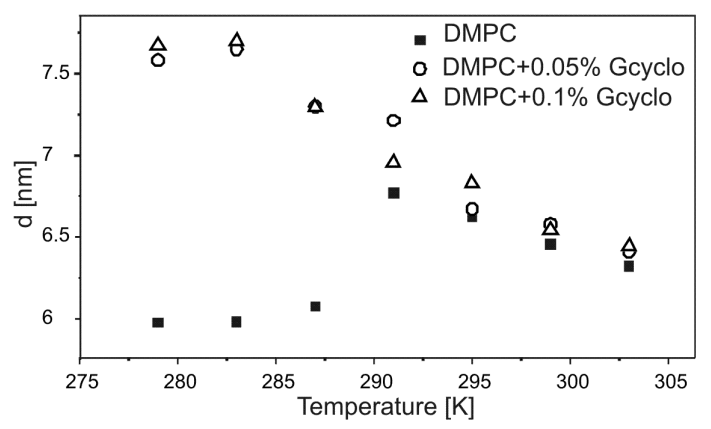

Fig. 7. Temperature dependence of the lamellar lattice constant $d$ of fully hydrated DMPC dispersion and the DMPC-Gcyclo mixtures.

was manifested by disappearance of the strong diffraction maxima. Figures 3 and 4 present the SAXS curves recorded for DMPC/gemini surfactant systems with 0.05 and $0.1 \%$ Gcyclo concentrations. For low concentration of the surfactant $(0.05 \%, 0.1 \%)$ in the system, the corre-

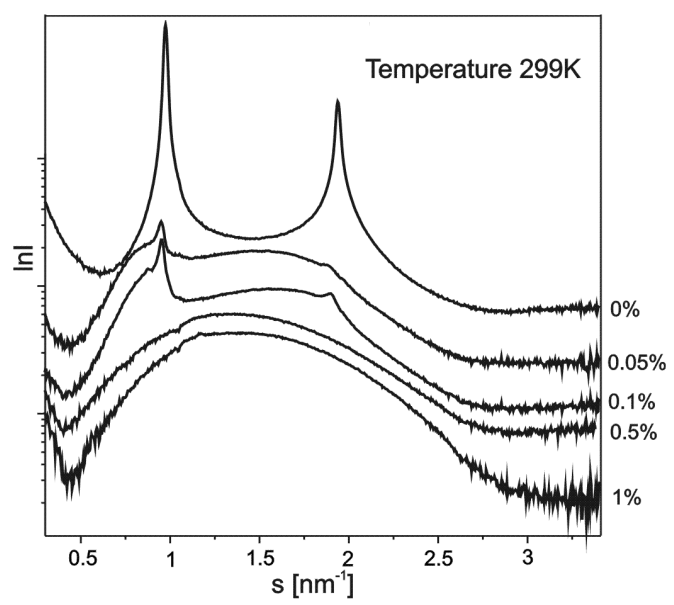

Fig. 8. Comparison of SAXS results for DMPC/Gcyclo $/ \mathrm{D}_{2} \mathrm{O}$ systems at $291 \mathrm{~K}$. 
sponding lamellar lattice constant increased up to $7.7 \mathrm{~nm}$ (DMPC $/ 0.1 \%$ Gcyclo, $T=283 \mathrm{~K}$ ).

For the increased surfactant concentration in the systems ( $0.5 \%$ and $1 \%$ Gcyclo) the gradual disappearance of the lamellar structure can be observed (Figs. 5, 6 and 8). For DMPC $/ 0.5 \%$ Gcyclo $/ \mathrm{D}_{2} \mathrm{O}$ system the SAXS data show the characteristic broad maximum, which is typical of single bilayers in the absence of stacking [32]. A similar very broad peak is observed also in scattering patterns of DMPC with $1 \%$ concentration of Gcyclo.

Similar gradual disappearance of the lamellar phase with increasing surfactant concentration was previously observed by us for other surfactant-phospholipid systems $[6,11]$

\section{Conclusion}

The addition of the surfactant studied implied a gradual disappearance of the lamellar phase typical of DMPC and a probable formation of the unilamellar vesicles (bicellar phase). Also the temperature range of the main phase transition of DMPC was shifted towards lower temperatures with increasing surfactant concentration.

The observed scattering patterns of DMPC/surfactant systems are very similar to the SAXS patterns reported for the bicellar DMPC/DHPC systems.

\section{Acknowledgments}

The research (the data collection at Beam Line I711) leading to these results has received funding from the European Community's Seventh Framework Programme (FP7/2007-2013) under grant agreement no. 226716. The research of A.S. was supported partially by university grant: DS./32/007/2009.

\section{References}

[1] R. Koynova, M. Caffrey, BBA-Rev. Biomembranes 1376, 91 (1998).

[2] J. Swenson, F. Kargl, P. Berntsen, C. Svanberg. J. Chem. Phys. 129, 045101 (2008).

[3] J. Katsaras, T.A. Harroun, J. Pencer, M.P. Nieh, Naturwissenschaften 92, 355 (2005).

[4] M. Kozak, M. Kempka, M. Szpotkowski, S. Jurga. J. Non-Cryst. Solids 353, 4246 (2007).

[5] R.D. Harvey, R.K. Heenan, D.J. Barlow, M.J. Lawrence, Langmuir 20, 9282 (2004).

[6] M. Kozak, K. Szpotkowski, A. Kozak, R. Zieliński, D. Wieczorek, M.J. Gajda, L. Domka, Radiat. Phys. Chem. 78, S129 (2009).

[7] K. Kato, P. Walde, N. Koine, S. Ichikawa, T. Ishikawa, R. Nagaharna, T. Ishihara, T. Tsujii, M. Shudou, Y. Omokawa, T.T. Kuroiwa, Langmuir 24, 10762 (2008).

[8] O. Lopez, M. Cocera, E. Wehrli, J.L. Parra, A. de la Maza, Archiv. Biochem. Biophys. 367, 153 (1999).
[9] J. Singh, Z. Unlu, R. Ranganathan, P. Griffiths, J. Phys. Chem. B 112, 3997 (2008).

[10] G. Klose, B. Madler, H. Schafer, K.P. Schneider, J. Phys. Chem. B 103, 3022 (1999).

[11] M. Kozak, A. Wypych, K. Szpotkowski, S. Jurga, A. Skrzypczak, J. Non-Cryst. Solids 356, 747 (2010).

[12] B. Madler, H. Binder, G. Klose, J. Coll. Interface Sci. 202, 124 (1998).

[13] K. Szpotkowski, M. Kozak, A. Kozak, R. Zieliński, D. Wieczorek, S. Jurga, Acta Phys. Pol. A 115, 561 (2009).

[14] B. Rozycka-Roszak, A. Przyczyna, Chem. Phys. Lipids 123, 209 (2003).

[15] S.Q. Wang, J.B. Huang, Q. Song, H.L. Fu, J. Coll. Interface Sci. 311, 296 (2007).

[16] H.H. Chang, R.K. Bhagat, R. Tran, P. Dea, J. Phys. Chem. B 103, 3022 (1999).

[17] R. Zana, Adv. Colloid Interface Sci. 97, 205 (2002).

[18] S.D. Wettig, R.E. Verrall, M. Foldvari, Curr. Gene Therapy 8, 9 (2008).

[19] I. Badea, R. Verrall, M. Baca-Estrada, S. Tikoo, A. Rosenberg, P. Kumar, M. Foldvari, J. Gene Med. 7, 1200 (2005).

[20] P. Luciani, C. Bombelli, M. Colone, L. Giansanti, S. Ryhaenen, V.M.J. Saily, G. Mancini, P.K.J, Kinnunen, Biomacromolecules 8, 1999 (2007).

[21] D. Uhríková, I. Zajac, M. Dubnicková, M. Pisarcik, S.S. Funari, G. Rapp, P. Balgavý, Coll. Surf. B 42, 59 (2005).

[22] E. Urbanik, J. Zabielska-Matejuk, A. Skrzypczak, J. Pernak, Mater. Organismen 31, 246 (1997).

[23] N. Rabjohn, Organic Synthese. Coll. Vol. 4, Wiley, New York 1963, p. 748.

[24] M. Królikowska, J. Garbarczyk, Z. Kristallogr. NCS 220, 103 (2005).

[25] Á. Csiszár, E. Klumpp, A. Bota, K. Szegedi, Chem. Phys. Lipids 126, 155 (2003).

[26] Y. Cerenius, K. Ståhl, L.A. Svensson, T. Ursby, A. Oskarsson, J. Albertsson, A. Liljas, J. Synchrotron Rad. 7, 203 (2000).

[27] M. Knaapila, C. Svensson, J. Barauskas, M. Zackrisson, S.S. Nielsen, N. Nørgaard Toft, B. Vestergaard, L. Arleth, Y. Cerenius, J. Synchrotron Rad. 16, 498 (2009).

[28] T.C. Huang, H. Toraya, T.N. Blanton, Y. Wu, J. Appl. Crystallogr. 26, 180 (1993).

[29] P.V. Konarev, V.V. Volkov, A.V. Sokolova, M.H.J. Koch, D.I. Svergun, J. Appl. Crystallogr. 36, 1277 (2003).

[30] S. Lesieur, D. Charon, P. Lesieur, C. Ringard-Lefebvre, V. Muguet, D. Duchene, D. Wouessidjewe, Chem. Phys. Lipids 106, 127 (2000).

[31] J. Eisenblätter, R. Winter. Biophys. J. 90, 956 (2006).

[32] J. Bolze, T. Fujisawa, T. Nagao, K. Norisada, H. Saito, A. Naito, Chem. Phys. Lett. 329, 215 (2000). 